\title{
Three-dimensional echocardiography using single-heartbeat modality decreases variability in measuring left ventricular volumes and function in comparison to four-beat technique in atrial fibrillation
}

Kambiz Shahgaldi ${ }^{1,4^{*}}$, Aristomenis Manouras ${ }^{1,2,4}$, Anna Abrahamsson², Petri Gudmundsson ${ }^{3}$, Lars-Åke Brodin ${ }^{4}$, Reidar Winter ${ }^{1,2}$

\begin{abstract}
Background: Three dimensional echocardiography (3DE) approaches the accuracy of cardiac magnetic resonance in measuring left ventricular (LV) volumes and ejection fraction (EF). The multibeat modality in comparison to single-beat (SB) requires breath-hold technique and regular heart rhythm which could limit the use of this technique in patients with atrial fibrillation (AF) due to stitching artifact. The study aimed to investigate whether SB full volume 3DE acquisition reduces inter- and intraobserver variability in assessment of LV volumes and EF in comparison to four-beat (4B) ECG-gated full volume 3DE recording in patients with AF.

Methods: A total of 78 patients were included in this study. Fifty-five with sinus rhythm (group A) and 23 having AF (group B). AB and SB 3DE was performed in all patients. LV volumes and EF was determined by these two modalities and inter- and intraobserver variability was analyzed.

Results: SB modality showed significantly lower inter- and intraobserver variability in group B in comparison to 4B when measuring LV volumes and EF, except for end-systolic volume (ESV) in intraobserver analysis. There were significant differences when calculating the LV volumes $(p<0.001)$ and EF $(p<0.05)$ with SB in comparison to 4B in group B.
\end{abstract}

Conclusion: Single-beat three-dimensional full volume acquisition seems to be superior to four-beat ECG-gated acquisition in measuring left ventricular volumes and ejection fraction in patients having atrial fibrillation. The variability is significantly lower both for ejection fraction and left ventricular volumes.

\section{Background}

Accurate quantification of LV volumes and EF has important diagnostic, prognostic and therapeutic implications. The variety of therapeutic decisions should be on the basis of LV volume and EF measures in various patient groups [1]. 2DE is today the most widely used modality for measuring LVEF, LV end-diastolic volume (EDV) and LVESV. However, 3DE is increasingly

\footnotetext{
* Correspondence: kambiz.shahgaldi@karolinska.se

'Department of Cardiology, Karolinska University Hospital Huddinge,

Stockholm, Sweden

Full list of author information is available at the end of the article
}

available, and several reports have demonstrated the superiority of 3DE regarding LV volume and EF measurements [2-9].

The most commonly used 3DE method for volume and EF measurement is to use real-time ECG-gated volume stitching from four consecutive $4 \mathrm{~B}$ with the purpose to maintain an acceptable spatial and temporal resolution [7]. The recently developed SB method has some potential advantages, despite suffering from some degree of decreased spatial and temporal resolution. This modality will further advance the assessment of LV by improving the speed of 
acquisition and reducing stitching artifacts. This is especially true for patient in AF.

Assessment of LVEF during AF has conventionally proved difficult because of beat-to-beat variation [10-13]. Due to the variability, the standard protocol for obtaining an accurate assessment of LV function during AF involves averaging a random number of consecutive cardiac cycles. The result is usually unreliable because the averaged value is dependent on a selected window of cardiac cycles and the mean number of cardiac cycles required in $\mathrm{AF}$ is approximately 3 times that required in sinus rhythm (SR) [14]. It is time-consuming and not realistic in the clinical scenario to analyze more than 10 beats for evaluating LV performance. It is well known that LVEF during AF varies depending on the preceding cardiac cycle length $[15,16]$. In clinical practice in AF patients, LVEF is commonly measured from a single beat either using a visual assessment for targeting a specific heart beat having a visually assessed representative $\mathrm{EF}$, or looking for an average R-R interval for the representative heart beat to measure from. Thus in AF patients particularly, 3DE becomes impractical for these reasons. However, SB could have an advantage over $4 \mathrm{~B}$ since it is possible to choose a representative heart beat similarly to $2 \mathrm{DE}$, and furthermore due to the lack of stitching artifact.

The study sought to investigate whether SB full volume 3DE acquisition reduces inter- and intraobserver variability when measuring $L V$ volumes and $E F$ in comparison to 4B ECG-gated full volume 3DE recording in patients with AF.

\section{Method}

We included fifty-five consecutive adult patients (37 men and 18 women, aged $53 \pm 17$ years of age, group A) having SR ( $67 \pm 10$ beats/sec) who were referred to the echocardiographic examinations on varying clinical reasons (Table 1) at the Department of Cardiology, Karolinska university Hospital, Huddinge. We also included twenty-three patients (12 men and 11 women,

Table 1 Clinical characteristics of the study population

\begin{tabular}{lcc}
\hline & Group A & Group B \\
\hline Age (years) & $53 \pm 17$ & $65 \pm 12$ \\
Males (\%) & 67 & 52 \\
Heart rate (bpm) & $67 \pm 10$ & $97 \pm 27$ \\
Indication of echo study (\%) & 60 & \\
Suspected heart failure & 15 & 29 \\
MurmurNalvular heart disease & 5 & 8 \\
Suspicion of Left ventricular thrombus & 10 & 0 \\
Routine control of transplanted heart patients & 0 & 20 \\
Unspecific exclusion of cardiac pathology & 10 & 20 \\
Other &
\end{tabular}

aged $65 \pm 12$ years of age, group B) having AF (97 \pm 27 beats/sec). Contrast agents were not used in this study. The study protocol was approved by the ethics committee of Karolinska University Hospital, Stockholm, Sweden, and all patients gave informed consent. Clinical characteristics of the study population are displayed in Table 1.

A complete 2DE and Doppler study was performed in all patients, using a commercially available Vivid E9 ultrasound machine (GE Healthcare, Horten, Norway) equipped with M5S probe. All acquisitions were performed by the same experienced operator with the patients in the left lateral position. Data sets were stored digitally for off-line analysis using commercially available software (EchoPAC PC version 108.1.4, GE Healthcare).

A novel $3 \mathrm{~V}$ matrix-array transducer was used for acquiring the 3D images. Gain and compression controls, as well as time gain compensation settings were optimized to enhance image quality.

A full volume scan was acquired from four consecutive cardiac cycles (fig. 1A) and 1 cardiac cycle, single-beat (fig. 1B) immediately after each other for each patient during end expiration breath-hold. Volume analysis was made using a commercially available semi-automated analysis tool, $4 \mathrm{D}$ auto $\mathrm{LV}$ volume quantification (4DLVQ, EchoPAC PC version 108.1.4, GE Healthcare) which has previously been validated $[17,18]$. The ED frames for contour detection were automatically displayed in quad-view: apical four-, two-chamber, three-chamber and LV shortaxis plane (fig. 2). Manual positioning by translating the four-chamber plane was first performed in order that the corresponding intersection line of all planes was placed in the middle of LV cavity, crossing the LV apex and the centre of mitral valve opening in each view. The software required manual input of three points for each of the three apical planes (two points at mitral annulus borders, and one at the apex) first in ED frames, and then continuing for ES frames. The software automatically delineates the LV endocardial border in a 3D-model from ED and ES phases. In cases where the automatic delineation of the endocardial border was considered suboptimal the borders could be adjusted manually. LVEDV, LVESV and EF were finally displayed.

Two readers analyzed the 3D images twice blinded to all clinical data and previous reading. All measurements were made twice one week apart.

\section{Statistical analysis}

All data are expressed as mean \pm SD. Bland and Altman analysis was performed to determine the systematic bias and limits of agreement of LV volumes and EF between the different methods [19]. In order to determine reproducibility all measurements were analyzed twice with one week apart blinded to the results of the first 

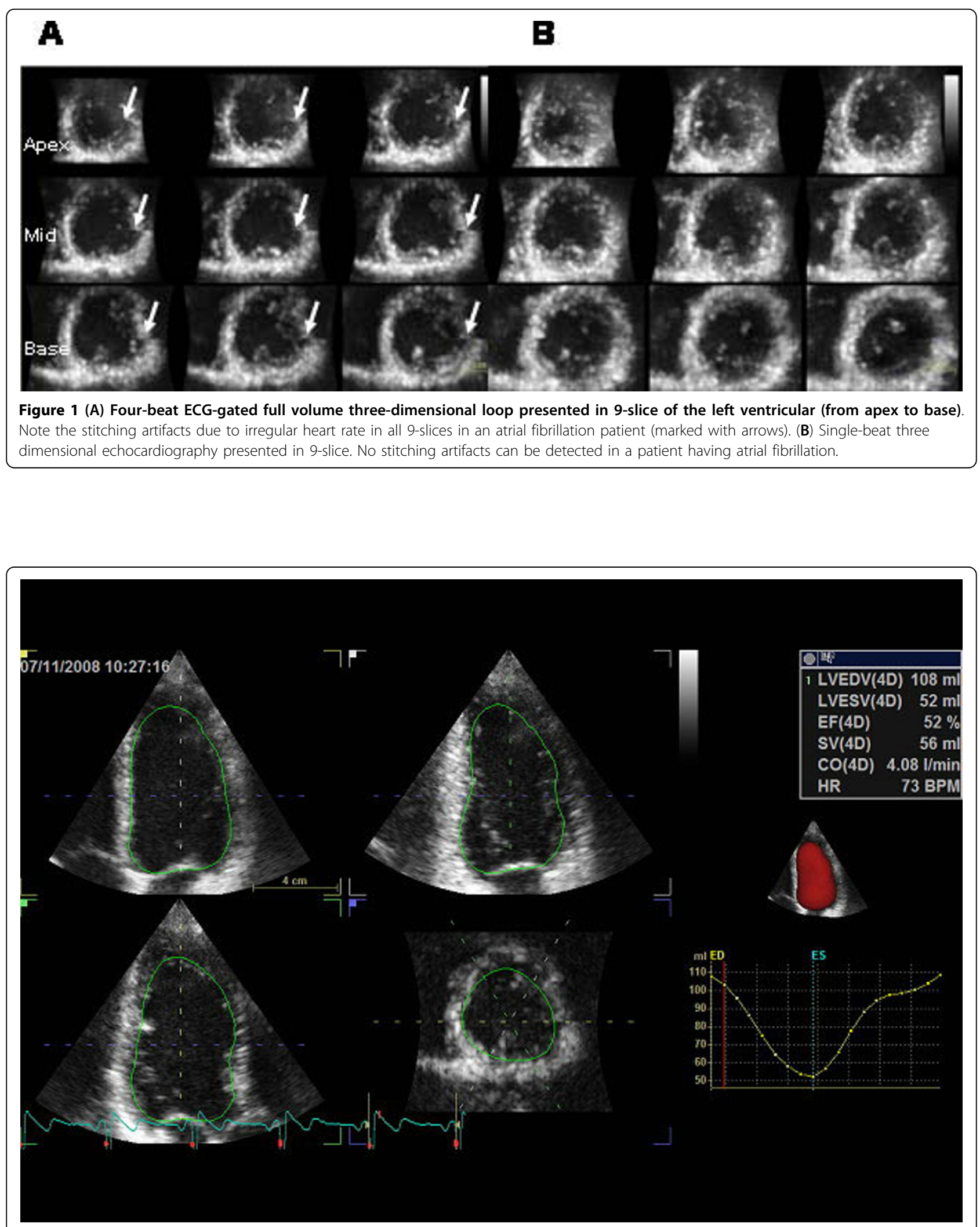

Figure 2 Quad view presentation of left ventricular using 4D auto LVQ software for measurement of left ventricular volumes and ejection fraction with three-dimensional echocardiography. Volume time-plot and quantitative analysis and three-dimensional model are presented in the right panel. 
observer. The inter- and intraobserver variability was measured according to the following formula: $\left(\mathrm{SD}_{\text {diff }} \times\right.$ $100 \%$ )/total mean $\times \sqrt{2}$ (Dahlberg's formula) [20], where $\mathrm{SD}_{\text {diff }}$ is the $\mathrm{SD}$ of difference between measurements. All variables were tested for normality using the Kolmogorov-Smirnov test. Different echocardiographic data were tested using paired t-tests. The significance level was set as $\mathrm{p}<0.05$. Statistical analysis was performed using standard statistical software (SPSS version 16.0, Inc, Chicago, IL).

\section{Results}

Echocardiographic analyses were successfully completed in seventy patients. Five patients in group A and three patients in group B were excluded from the study due to poor acoustic window or because clear endocardial border visualization was difficult (two segments or more). Average image time resolution for $4 \mathrm{~B}$ was $72 \pm$ 18 volumes per second, whereas for SB data sets were acquired at $21 \pm 5$ volumes per second.

The mean EDV, ESV and EF in group A using 4B and $\mathrm{SB}$ is presented in table 2. Statistical analysis showed no significant difference between the variables using $4 \mathrm{~B}$ in comparison to SB.

The mean EDV, ESV and EF by $4 \mathrm{~B}$ and $\mathrm{SB}$ in group $\mathrm{B}$ are demonstrated in table 2. Statistical analysis showed significant differences between EDV, ESV $(p<0.001)$ and $\mathrm{EF}(\mathrm{p}<0.05)$ by $4 \mathrm{~B}$ in comparison to SB.

The limits of agreement analysis of LV volumes and EF in group B by different methods are shown in table 3. In group B there was a mean difference of $-32.5 \pm$ $15 \mathrm{ml}$ for EDV by the two different techniques and $-12.2 \pm$ $10.5 \mathrm{ml}$ for ESV and $-7 \pm 10 \%$ for $\mathrm{EF}$ (fig. $3 \mathrm{~A}, \mathrm{~B}$ and $3 \mathrm{C}$ ).

\section{Reproducibility}

The total patient population both in group A and B were analyzed to determine interobserver reproducibility. Intra- and interobserver variability in group A and B

Table 2 Mean \pm SD values for left ventricular enddiastolic volume $(\mathrm{ml})$, end-systolic volume $(\mathrm{ml})$ and ejection fraction (\%) for the different imaging strategies

\begin{tabular}{lllll}
\hline & EDV (ml) & ESV (ml) & EF (\%) & HR (bpm) \\
\hline Group A & & & & \\
Four-beat full volume & $102 \pm 25$ & $47 \pm 19$ & $54 \pm 10$ & $67 \pm 10$ \\
Single-beat full volume & $99 \pm 25$ & $47 \pm 20$ & $53 \pm 10$ & $67 \pm 11$
\end{tabular}

\section{Group B}

Four-beat full volume $\quad 87 \pm 27^{* * *} \quad 52 \pm 22^{* * *} \quad 41 \pm 11^{*} \quad 97 \pm 27$

Single-beat full volume $\quad 119 \pm 34 \quad 64 \pm 27 \quad 47 \pm 12 \quad 97 \pm 26$

EDV: end-diastolic volume, ESV: end-systolic volume, EF: ejection fraction, HR: heart rate,

${ }^{* * *} p<0,0001$ vs. end-diastolic, end-systolic volume and $* p<0.05$ vs. ejection fraction by single beat.
Table 3 Mean differences $(\mathrm{ml})$ and limits of agreement (mean \pm SD) in left ventricular volumes and ejection fraction measured by single beat and four-beat ECGgated three-dimensional echocardiography in patients with atrial fibrillation

\begin{tabular}{lccc}
\hline & $\begin{array}{c}\text { Group B } \\
\text { EDV 4B - EDV } \\
\text { SB }\end{array}$ & $\begin{array}{c}\text { Group B } \\
\text { ESV 4B - ESV } \\
\text { SB }\end{array}$ & $\begin{array}{c}\text { Group B } \\
\text { EF 4B - EF } \\
\text { SB }\end{array}$ \\
\hline $\begin{array}{l}\text { Mean difference } \pm \\
\text { SD }\end{array}$ & $-32.5 \pm 15$ & $-12.2 \pm 10.5$ & $-7 \pm 10$ \\
Limits of agreement & -62.5 to -2.5 & -33.2 to 8.8 & -27 to 13 \\
\hline
\end{tabular}

EDV: end-diastolic volume, ESV: end-systolic volume, EF: ejection fraction, $4 B$ : four-beat, $S B$ : single-beat.

using $4 \mathrm{~B}$ and $\mathrm{SB}$ is presented in table 4. Statistical analysis showed no significant differences between the intraand interobserver variability in group A. Although, there were significant differences in inter- and intraobserver variability in all three variables in group B except ESV analyzed by intraobserver variability.

There were no significant differences in heart rate during acquisition period by $4 \mathrm{~B}$ and SB modality.

\section{Discussion}

To our knowledge, this is the first study comparing two 3DE techniques side-by-side, $4 \mathrm{~B}$ and SB in AF. Currently, quantitative measurements of LV size and function are most commonly obtained using the biplane Simpson's rule [21] with 2D transthoracic echocardiography, which is highly dependent on operator technique and which can be limited by poor acoustic windows and the need for geometric assumptions. Volumetric methods of image acquisition by 3DE have demonstrated substantial improvements in accuracy and reproducibility over 2DE $[22,23]$.

In this study, LV volumes and EF in group A were comparable in these two different acquisition techniques (4B and SB respectively) without any significant differences. This finding is not in concordance by a recent publication by Macron L et al. [24]. The only explanation is that we had higher time resolution using the SB modality which prevented over/underestimation of LV volumes. SB showed a tendency to a lower inter- and intraobserver variability when measuring $L V$ volumes in comparison to the $4 \mathrm{~B}$ technique in group $\mathrm{A}$, although, this was not statistically significant. Previous studies have shown the low inter- and intraobserver variablity of LV volumes and EF measurements using 3DE in patient with SR [25-27]. To our knowledge, there are no studies investigating variability of measuring LV volume and EF in AF patients using 3DE. In our study we demonstrated significantly lower intra- and interobserver variability of $\mathrm{LV}$ volumes and $\mathrm{EF}$ using $\mathrm{SB}$ in comparison to $4 \mathrm{~B}$ in patients having AF, except for ESV analysed by intraobserver variability measurement. 


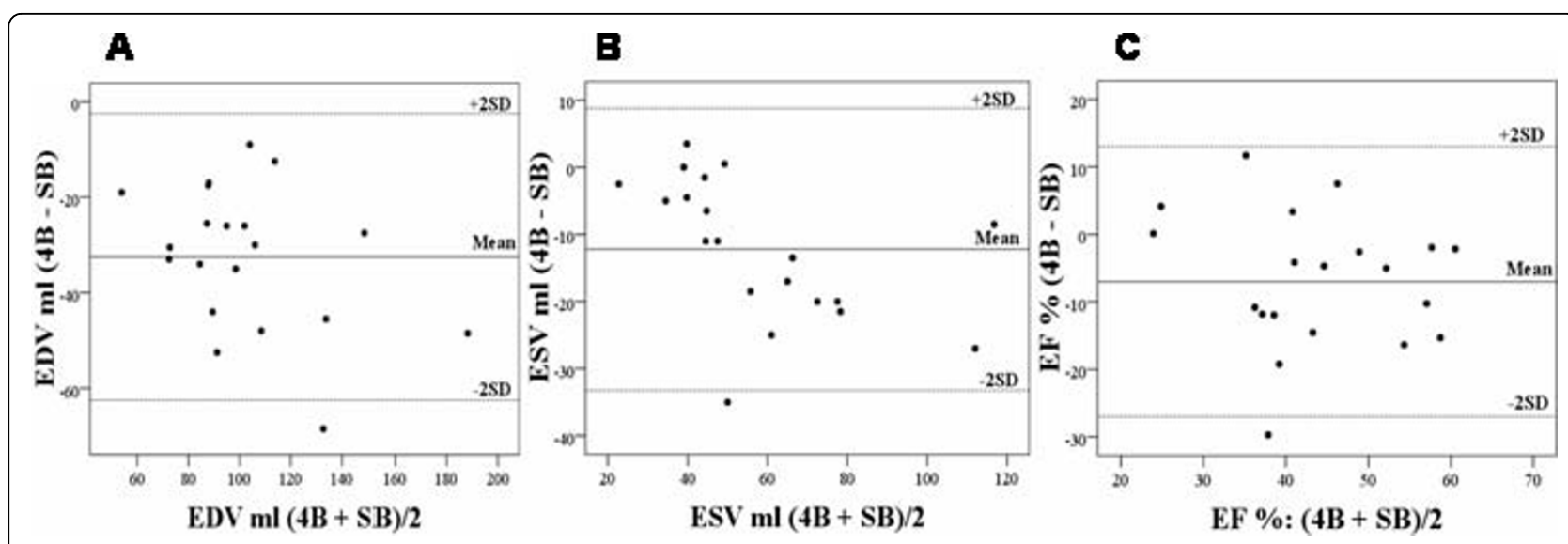

Figure 3 A-C. Bland-Altman plot of differences between end-diastolic volume (A), end-systolic volume (B) and ejection fraction (C) determined by four-beat and and single-beat three-dimensional echocardiography in atrial fibrillation patients.

EF measurements in AF patients are challenging in clinically practice due to the need of measuring an average of heart beats [14]. From a practical point of view, experienced echocardiographer can overcome this difficulty by selecting visually estimated representative heart beat for EF measurement. Thus in AF patients particularly, 4B becomes impractical for these reasons. However, SB could have an advantage over $4 \mathrm{~B}$ since it is possible to choose a representative heart beat similarly to $2 \mathrm{DE}$, and furthermore due to the lack of stitching artifacts.

Table 4 Intra- and interobserver reproducibilities for left ventricular volumes and ejection fraction by single- and four-beat three-dimensional echocardiography

\begin{tabular}{llll}
\hline EDV $(\mathrm{ml})$ & ESV $(\mathrm{ml})$ & EF (\%) \\
\hline
\end{tabular}

\section{Group A}

Intraobserver variability (\%)

$\begin{array}{llll}\text { Four-beat full volume } & 4.4 & 5.1 & 3.4\end{array}$

Single-beat full volume

$\begin{array}{lll}3.9 & 4.6 \quad 4.1\end{array}$

Group A

Interobserver variability (\%)

Four-beat full volume

Single-beat full volume

\section{Group B}

Intraobserver variability (\%)

Four-beat full volume

Single-beat full volume

\section{$9^{*}$}

4.5

11.4

2.9

$8.3^{* *}$

4.8

\section{Group B}

Interobserver variability (\%)

$\begin{array}{llll}\text { Four-beat full volume } & 10.4^{*} & 15.2^{*} & 17.9^{* *}\end{array}$

Single-beat full volume

7.2

5.6

EDV: end-diastolic volume, ESV: end-systolic volume and EF: ejection fraction, ${ }^{*} p<0.05$ and ${ }^{* *} p<0.001$.
In group B we found significant differences in EDV, ESV and EF when comparing $4 \mathrm{~B}$ vs. SB which was not surprising considering to beat-to-beat variation. The mean differences were rather poor, $-32.5 \pm 15 \mathrm{ml}$ for EDV, $-12.2 \pm 10.5 \mathrm{ml}$ for ESV and $-7 \pm 10 \%$ for EF between $4 \mathrm{~B}$ and $\mathrm{SB}$, especially considering that this patient population had normal LV volumes. Additionally, CI for the respective measurements was rather wide, $65 \mathrm{ml}, 42 \mathrm{ml}$ and $40 \%$ respectively. Again, this is expected in AF patients and this study was not addressed to investigate this issue. Furthermore, LV volumes and EF using $4 \mathrm{~B}$ were significantly smaller in comparison to SB ( $\mathrm{p}<0.0001$ for LV-volumes and $\mathrm{p}<$ 0.05 for EF). From clinical point of view, perhaps the most important finding in this study is the lower variability of SB in comparison to $4 \mathrm{~B}$ when measuring $\mathrm{LV}$ volumes and EF in AF (e.g. 5.6\% vs. $17.9 \%$ for EF determination, interobserver variability, $\mathrm{p}<0.001)$. One explanation might be that the software has difficulties in tracking the endocardial border in AF when gathering volume in $4 \mathrm{~B}$ because of stitching artifacts due to the irregular heart rate (fig. 1A). The geometrical model in 4D LVQ is flexible and allows a wide variety of shapes. Although, the software has difficulties in achieving the accurate balance between smooth surfaces and surfaces that are improbable [28]. Another explanation could be that prolonged acquisition time using $4 \mathrm{~B}$ increase the chance of patient motion or artifatcs, resulting in unsuccesfull 3D image reconstruction, which can be overcome using SB [29]. There is a significant user dependency in image quality in echocardiography, i.e. small changes in manual optimization can have a large impact in image quality. The beat-to-beat variability might create a poorer image quality from cardiac movement throughout the $4 \mathrm{~B}$ acquisition. Interestingly, the LV volumes and EF is significantlly smaller with $4 \mathrm{~B}$ in comparison to 
SB. This finding is difficult to explain from any other source than software algorithm, since the measured heart beat was not deliberately selected. In other words, there is no reason to believe that there would be any differences in LV volumes between the methods. The only two possible explanations are either random findings or more probable systematic software error. Providing that this is true, there should be additional advantage in measuring more true volumes when using SB acquisition in patients with irregular heart rhythm.

\section{Limitations}

We have only analyzed our data using the GE equipment/software and this is likely that the effect might depend upon the software and equipment being used.

There are today three software packages from three different vendor's commercially available for the measurement of 3D data. These softwares work with different algorithm and are not automatically interchangeable. To avoid future problems with vendor's specific results this should be tested separately or ideally it would desirable to use same algorithms.

We have not been able to measure the R-R interval in the each three-dimensional modality since this was not possible using the current software. A more robust testretest variablity would perhaps been if the patients were rescanned and separate datasets acquired and analysed. This might be a true analysis of test-retest variability and would be more clinically relevant.

\section{Clinical implications}

SB modality is a relatively new 3DE technique which reduces intra- and interobserver variability in patients with irregular heart rhythm. SB leads to loss of stitching artifact and reduces the acquisition time. Therefore, when $3 \mathrm{DE}$ is used in clinical practice in AF patients, SB modality should be recommended before multi-beat technique.

\section{Conclusion}

Single-beat three-dimensional full volume acquisition seems to be superior to four-beat ECG -gated acquisition in measuring LV volumes and EF in patients having atrial fibrillation. The variability is significantly lower both for EF and LV volumes. More studies are needed to confirm this before implementing single-beat in every day clinical practice.

\footnotetext{
Author details

'Department of Cardiology, Karolinska University Hospital Huddinge, Stockholm, Sweden. ${ }^{2}$ Department of Clinical Physiology, Karolinska University Hospital Huddinge, Stockholm, Sweden. ${ }^{3}$ Department of Biomedical Laboratory Science, Malmö University, Malmö, Sweden. ${ }^{4}$ School of Technology and Health, Royal Institute of Technology, Huddinge, Sweden.
}

\section{Authors' contributions}

RW and KS introduced the study idea. KS acquired the ultrasound images. $\mathrm{AA}$ and $\mathrm{KS}$ performed the off-line analysis. AM helped in the interpretation of the results and statistical analysis. KS wrote the manuscript, RW and PG added clinical discussion to the manuscript. LÅB reviewed the manuscript. Finally, all authors read and approved the manuscript.

\section{Competing interests}

The authors declare that they have no competing interests.

Received: 17 September 2010 Accepted: 5 October 2010 Published: 5 October 2010

\section{References}

1. Gregoratos G, Abrams J, Epstein AE, Freedman RA, Hayes DL, Hlatky MA, Kerber RE, Naccarelli GV, Schoenfeld MH, Silka MJ, Winters SL: ACC/AHA/ NASPE 2002 guideline update for implantation of cardiac pacemakers antiarrhythmia devices: summary article. A report of the American College of Cardiology/American Heart Association Task Force on Practice Guidelines (ACC/AHA/NASPE Committee to Update the 1998 Pacemaker Guidelines). J Cardiovasc Electrophysiol 2002, 13:1183-1199.

2. Nikitin NP, Constantin C, Loh PH, Ghosh J, Lukaschuk El, Bennett A, Hurren S, Alamgir F, Clark AL, Cleland JG: New generation 3-dimensional echocardiography for left ventricular volumetric and functional measurements: comparison with cardiac magnetic resonance. Eur J Echocardiogr 2006, 7:365-72.

3. Tighe DA, Rosetti M, Vinch CS, Chandok D, Muldoon D, Wiggin B, Dahlberg ST, Aurigemma GP: Influence of image quality on the accuracy of real time three-dimensional echocardiography to measure left ventricular volumes in unselected patients: a comparison with gatedSPECT imaging. Echocardiography 2007, 24:1073-80.

4. Jacobs LD, Salgo IS, Goonewardena S, Weinert L, Coon P, Bardo D, Gerard O, Allain P, Zamorano JL, de Isla LP, Mor-Avi V, Lang RM: Rapid online quantification of left ventricular volume from real-time threedimensional echocardiographic data. Eur Heart J 2006, 27:460-8.

5. Pouleur AC, le Polain, de Waroux JB, Pasquet A, Gerber BL, Gérard O, Allain $P$, Vanoverschelde $J$ : Assessment of left ventricular mass and volumes by three-dimensional echocardiography in patients with or without wall motion abnormalities: comparison against cine magnetic resonance imaging. Heart 2008, 94:1050-7.

6. Chan J, Jenkins C, Khafagi F, Du L, Marwick TH: What is the optimal clinical technique for measurement of left ventricular volume after myocardial infarction? A comparative study of 3-dimensional echocardiography, single photon emission computed tomography, and cardiac magnetic resonance imaging. J Am Soc Echocardiogr 2006, 19:192-201.

7. Kühl HP, Schreckenberg M, Rulands D, Katoh M, Schäfer W, Schummers G, Bucker A, Hanrath P, Franke A: High-resolution transthoracic real-time three-dimensional echocardiography: quantitation of cardiac volumes and function using semi-automatic border detection and comparison with cardiac manetic resonance imaging. J Am Coll Cardiol 2004, 43:2083-90.

8. Jenkins C, Bricknell K, Hanekom L, Marwick TH: Reproducibility and accuracy of echocardiographic measurements of left ventricular parameters using real-time three-dimensional echocardiography. J Am Coll Cardiol 2004, 44:878-86.

9. Jenkins C, Marwick TH: Baseline and follow-up assessment of regional left ventricular volume using 3-dimensional echocardiography: comparison with cardiac magnetic resonance. Cardiovascular Ultrasound 2009, 7:55.

10. Schneider J, Berger HJ, Sands MJ, Lachman AB, Zaret BL: Beat-to-beat left ventricular performance in atrial fibrillation: radionuclide assessment with the computerized nuclear probe. Am J Cardiol 1983, 51:1189-95.

11. Hardman SM, Noble MI, Seed WA: Postextrasystolic potentiation and its contribution to the beat-to-beat variation of the pulse during atrial fibrillation. Circulation 1992, 86:1223-32.

12. Muntinga HJ, Gosselink AT, Blanksma PK, De Kam PJ, Van Der Wall EE, Crijns HJ: Left ventricular beat to beat performance in atrial fibrillation: dependence on contractility, preload, and afterload. Heart 1999, 82:575-80.

13. Tabata T, Grimm RA, Asada J, Popovic ZB, Yamada H, Greenberg NL, Wallick DW, Zhang Y, Zhuang S, Mowrey KA, Thomas JD, Mazgalev TN: Determinants of LV diastolic function during atrial fibrillation: beat-to- 
beat analysis in acute dog experiments. Am J Physiol Heart Circ Physiol 2004, 286:H145-52

14. Dubrey SW, Falk RH: : Optimal number of beats for the Doppler measurement of cardiac output in atrial fibrillation. J Am SoC Echocardiogr 1997, 10:67-71.

15. Brookes Cl, White PA, Staples M, Oldershaw PJ, Redington AN, Collins PD, Noble MI: Myocardial contractility is not constant during spontaneous atrial fibrillation in patients. Circulation 1998, 98:1762-8.

16. Iwase M, Aoki T, Maeda M, Yokota M, Hayashi H: Relationship between beat to beat interval and left ventricular function in patients with atrial fibrillation. Int I Card Imaging 1998, 3:217-26.

17. Muraru D, Badano LP, Piccoli G, Gianfagna F, Del Mestre L, Ermacora D, Proclemer A: Validation of a novel automated border-detection algorithm for rapid and accurate quantification of left ventricular volumes based on three-dimensional echocardiography. Eur J Echocardiogr 2010, 11:359-68.

18. Hansegård J, Urheim S, Lunde K, Malm S, Rabben SI: Semi-automade quantification of left ventricular volumes and ejection fraction by realtime three-dimensional echocardiograohy. Cardiovascular Ultrasound 2009, $7(20): 18$.

19. Bland JM, Altman DG: Statistical methods for assessing agreement between two methods for clinical measurements. Lancet 1986, 1:307-10.

20. Dahlberg G: Statistical methods for medical and biological students. New York: Interscience Publications 1940.

21. Lang RM, Bierig, Devereux RB, Flachskampf FA, Foster E, Pellikka PA, Picard MH, Roman MJ, Seward J, Shanewise J, Solomon S, Spencer KT, John Sutton M, St Stewart W: Recommendations for chamber quantification. Eur J Echocardiogr 2006, 7:79-108.

22. Arai $\mathrm{K}$, Hozumi T, Matsumura $\mathrm{Y}$, Sugioka $\mathrm{K}$, Takemoto $\mathrm{Y}$, Yamagishi $\mathrm{H}$, Yoshimaya M, Kasanuki H, Yoshikawa J: Accuracy of measurement of left ventricular volume and ejection fraction by new real-time threedimensional echocardiography in patients with wall motion abnormalities secondary to myocardial infarction. Am J Cardiol 2004, 94:552-558.

23. Chuang ML, Hibberd MG, Salton CJ, Beaudin RA, Riley MF, Parker RA, Douglas PS, Manning WJ: Importance of imaging method over imaging modality in noninvasive determination of left ventricular volumes and ejection fraction. J Am Coll Cardiol 2000, 35:477-84.

24. Macron L, Lim P, Bensaid A, Nahum J, Dussault C, Mitchell-Heggs L, DuboisRandé J-L, Deux J-F, Gueret P: Single-beat versus multibeat real-time 3D echocardiography for assessing left ventricular volumes and ejection fraction: a comparison study with cardiac magnetic resonance. Circ Cardiovasc Imaging 2010, 3(1):450-5.

25. Gopal AS, Shen Z, Sapin PM, Keller Am, Schnellbaecher MJ, Leibowitz DW, Akinboboye OO, Rodney RA, Blood DK, King DL: Assessment of cardiac function by three-dimensional echocardiography compared with conventional noninvasive methods. Circulation 1995, 92:842-53.

26. van den Bosch AE, Robbers-Visser D, Krenning BJ, Voormolen MM, McGhie JS, Helbing WA, Roos-Hesselink JW, Simoons ML, Meijboom FJ: Real-time transthoracic three-dimensional echocardiographic assessment of left ventricular volume and ejection fraction in congenital heart disease. J Am Soc Echocardiogr 2006, 19:1-6.

27. Soliman O, Kirschbaum SW, van Dalen BS, van der Zwaan HB, Delavary BM, Vletter WB, van Geuns R-JM, Ten Cate FJ, Geleijnse ML: Accuracy and reproducibility of quantification of left ventricular function by real-time three-dimensional echocardiography versus magnetic resonance. $\mathrm{Am} \mathrm{J}$ Cardiol 2008, 102:778-783.

28. Leung KY, Bosch JG: Automated border detection in three-dimension echocardiography: principles and promises. Eur J Echocardiogr 2010, 11:97-108.

29. Johri AM, Passeri JJ, Picard MH: Three-dimensional echocardiography: approaches and clinical utility. Heart 2010, 96:390-7.

\section{doi:10.1186/1476-7120-8-45}

Cite this article as: Shahgaldi et al:: Three-dimensional echocardiography using single-heartbeat modality decreases variability in measuring left ventricular volumes and function in comparison to four-beat technique in atrial fibrillation. Cardiovascular Ultrasound 2010 8:45.

\section{Submit your next manuscript to BioMed Central and take full advantage of:}

- Convenient online submission

- Thorough peer review

- No space constraints or color figure charges

- Immediate publication on acceptance

- Inclusion in PubMed, CAS, Scopus and Google Scholar

- Research which is freely available for redistribution

Submit your manuscript at www.biomedcentral.com/submit 